\title{
Establishment and Evaluation of Nomogram Model for Predicting the Risk of No Reflow after Percutaneous Coronary Intervention in Patients with Acute Myocardial Infarction
}

\author{
Z. ZHANG, Z. JI*, R. DU, X. M. WANG AND L. J. YAO \\ Department of Cardiovascular Medicine, Tangshan Gongren Hospital, Tangshan 063000, China
}

Zhang et al.: Percutaneous Coronary Intervention in Patients with Acute Myocardial Infarction

\begin{abstract}
To explore the establishment of nomogram prediction model for the risk of no-reflow after percutaneous coronary intervention in patients with acute myocardial infarction and to evaluate the discrimination and accuracy of the model. 327 patients with acute myocardial infarction who underwent emergency percutaneous coronary intervention in our hospital from January 2019 to March 2020 were selected as the research objects. According to whether the patients had no-reflow after percutaneous coronary intervention, they were divided into reflow group and no-reflow group. The risk factors of no-reflow were screened by single factor and multi factor logistic regression model and the nomogram prediction model of no-reflow risk was established based on the risk factors. The area under receiver operating characteristic curve was used to test the prediction effect of the model. Logistic regression model was used for multivariate analysis. The results showed that the number of coronary artery lesion, ischemic time, neutrophil percentage, white blood cell count, thrombus grade and vasospasm grade were independent risk factors affecting no-reflow $(\mathbf{p}<\mathbf{0 . 0 5})$. According to the risk factors affecting no-reflow screened by multivariate logistic regression, a nomographic model for predicting the risk of no-reflow was established by using $R$ software ( $R$ 3.6.3) regression modeling strategies package. The area under receiver operating characteristic curve was 0.860 with the maximum of Youden index as the best critical value of the prediction model. The calibration curve of nomogram was drawn. The calibration curve was a straight line with slope close to 1. Hosmer-Lemeshow goodness of fit test results showed that, $\chi^{2}=10.278, p=0.246$. Based on the risk factors affecting no-reflow after percutaneous coronary intervention in patients with acute myocardial infarction, including the number of coronary artery lesions, ischemic time, neutrophil percentage, white blood cell count, thrombus grade and vasospasm grade, this study established a nomogram prediction model. The model has good discrimination and consistency and can provide certain guidance for the prediction and preventive intervention of the risk of no-reflow after percutaneous coronary intervention.
\end{abstract}

Key words: Acute myocardial infarction, percutaneous coronary intervention, no-reflow, nomogram prediction model

Acute Myocardial Infarction (AMI) has a high mortality rate. Emergency Percutaneous Coronary Intervention (PCI) is mainly used in clinic treatment. PCI can relieve the stenosis and embolism of infarction related lumen in patients with myocardial infarction, rebuild blood flow and restore the blood flow to G3 of Thrombolysis In Myocardial Infarction (TIMI). However, there is still no blood perfusion or there is only partial recovery in myocardial tissue at infarction site of partial patients, namely "no-reflow". According to the survey data, the incidence of no-reflow after PCI in patients with AMI is about $15 \%-60 \%{ }^{[1]}$, which can increase the incidence of early congestive heart failure and cardiac death ${ }^{[2]}$. No- reflow can cause adverse events such as enlargement of myocardial infarction area, malignant arrhythmia and heart failure. It has become an important factor of increasing mortality after $\mathrm{PCI}^{[3]}$. At present, the mechanism of no-reflow phenomenon is still unclear and most scholars believe it is related to microvascular embolism, microvascular spasm and endothelial injury ${ }^{[4]}$. Therefore, it is of great significance for the formulation of preventive measures to screen out the relevant risk factors affecting no-reflow. At present, the clinical studies on risk factors affecting reflow are inconsistent and there are few reports on methods to establish the model for predicting the risk of no-reflow.

*Address for correspondence

E-mail: jizheng2020@163.com 
Nomogram is a prediction model based on the affecting factors selected by multi-factor regression analysis, which can visualize the contribution of each affecting factor to the outcome events. In current studies, it is mainly used in the risk prediction of lung complications after lung cancer operation ${ }^{[5]}$ and oral leukoplakia deterioration and metastasis ${ }^{[6]}$ and its accuracy and reliability have also been made clear. In this study, a nomogram prediction model was established based on the risk factors affecting no-reflow after PCI in patients with AMI, as reported below.

\section{MATERIALS AND METHODS}

\section{Research objects:}

327 patients with AMI who were treated in our hospital from January 2019 to March 2020 were selected as the research objects, including 253 males and 74 females, aged 39-82 y, with an average age of $(64.37 \pm 10.86) \mathrm{y}$. Inclusion criteria: all patients were admitted to hospital within $12 \mathrm{~h}$ after onset; clinically AMI meeting the diagnostic criteria established by the Chinese Society of Cardiology; complete clinical case data. Exclusion criteria: complicated with malignant tumor; allergic to related therapeutic drugs; historical PCI or congenital heart disease; complicated with blood system diseases.

\section{Methods:}

Coronary angiography and emergency PCI: Patients with AMI were given aspirin, clopidogrel and intravenous heparin before operation. Quantitative coronary angiography was used to evaluate the vascular condition.

Data collection: General conditions of patients, such as age, gender, Body Mass Index (BMI) and basic medical history, were recorded in detail. Before emergency PCI, venous blood of patients was taken. Neutrophil percentage, Mean Platelet Volume (MPV) and Platelet Count (PLT) of the blood were measured by Beckman Coulter UniCel DxH 800 automatic hematology analyzer. High Density Lipoprotein Cholesterol (HDL-C) and Low Density Lipoprotein Cholesterol (LDL-C) were measured by Beckman Coulter AU5800 automatic biochemical analyzer. Meanwhile, the angiographic results, the length of the vessel entering the lesion, the target lesion and the number of lesions were recorded.

According to the incidence of no-reflow, the patients were divided into no-reflow group and reflow group. Single-factor analysis and multi-factor logistic regression analysis were used to screen the risk factors affecting no-reflow.

Related definitions: No-reflow-according to TIMI blood flow grade, coronary angiography shows coronary blood flow $\leq$ TIMI G2 after emergency PCI in the case of contact stenosis and spasm after emergency PCI. TIMI G0-2 indicates no-reflow and TIMI G3 indicates normal blood flow.

Thrombus grade-TIMI thrombus grade is evaluated by Mehta standard. G0 is defined as no thrombus; G1 is defined as suspected thrombus; the thrombus with diameter $\leq 1 / 2$ of vessel diameter is defined as small thrombus and evaluated as G2; the thrombus with diameter $>1 / 2$ vessel diameter and less than 2 times of vessel diameter is medium thrombus and evaluated as G3; the thrombus with diameter $\geq 2$ times of vessel diameter is large thrombus and evaluated as G4 and the complete occlusion of vessel is evaluated as G5.

Vasospasm grade-The vasospasm grade has four grades, including G0, G1, G2 and G3, according to the severity of vasospasm (no vasospasm, mild vasospasm, server vasospasm and diffuse vasculopathy).

\section{Statistical analysis:}

SPSS 22.0 is used for analysis. Counting data is expressed in percentage (\%) and the $\chi^{2}$ test or Fisher exact probability method is adopted. The measurement data is represented by $(\overline{\mathrm{x}} \pm \mathrm{s})$ and two independent samples or paired samples are used for t-test, $\mathrm{p}<0.05$ indicates difference with statistical significance.

\section{RESULTS AND DISCUSSION}

Among 327 patients with AMI, 55 patients had noreflow after PCI, with the incidence rate of $16.82 \%$. According to the incidence of no-reflow, the patients were divided into two groups: no-reflow group $(n=55)$ and reflow group $(\mathrm{n}=272)$. According to single-factor analysis, the composition ratio of no-reflow complicated with diabetes, coronary artery three vessel diseases, thrombus G5 and vasospasm G3 in the no-reflow group was higher than that in the reflow group. In addition, the ischemia time in the no-reflow group was longer than that in the reflow group and the neutrophil percentage and white blood cell count in the no-reflow group were higher than those in the reflow group $(\mathrm{p}<0.05)$ (Table 1).

The significant variables concluded by single-factor analysis, such as complicated diabetes (yes $=0$, no $=1$ ), the number of coronary artery lesions (single vessel $=0$, double vessel $=1$, three vessel $=2$ ), the thrombus grade of $\mathrm{G} 5$ ( $\mathrm{G} 0=0, \mathrm{G} 1=1, \mathrm{G} 2=2, \mathrm{G} 3=3, \mathrm{G} 4=4, \mathrm{G} 5=5)$, vasospasm grade $(\mathrm{G} 0=0, \mathrm{G} 1=1, \mathrm{G} 2=2, \mathrm{G} 3=3)$, ischemic 
time, neutrophil percentage, white blood cell count, were taken as dependent variables and the incidence of re-flow was taken as independent variable. They were included into logistic regression model for multifactor analysis. The results showed that the number of coronary artery lesions, ischemia time, neutrophil percentage, white blood cell count, thrombus grade and vasospasm grade were independent risk factors affecting no-reflow $(\mathrm{p}<0.05)$, as shown in Table 2 . Finally, the formula, $1.094 \times$ number of coronary artery lesions (2) assignment $+0.368 \times$ ischemic time assignment $+0.065 \times$ neutrophil percentage assignment +0.284 white blood cell count assignment $+3.149 \times$ thrombus G4 assignment $+3.544 \times$ thrombus G5 assignment $+2.138 \times$ vasospasm G2 assignment $+1.974 \times$ vasospasm G3 assignment-13.418, was obtained (Table 2).

Based on multi-factor logistic regression analysis, the screened risk factors affecting no-reflow were used to establish the nomogram model for predicting the risk of no-reflow by using $\mathrm{R}$ software (R3.6.3) regression modeling strategies (rms) package, as shown in fig. 1. The predicted probability value corresponding to the sum of the integral of each prediction index was the predicted incidence risk rate. The influence weight increased by 8.5 points for every $1 \mathrm{~h}$ of ischemia time, 7.6 points for every $5 \%$ increase of neutrophil count and 6.3 points for every $1 \times 109$ increase of white blood cell count. It was 0 points for $\mathrm{G} 0$ of thrombus grade and increased by 17 points for G1, 27 points for G2, 28 points for G3, 67.5 points for G4 and 77.6 points for G5; taking single coronary artery lesion as a reference, the influence weight increased by 20 points for double vessel lesion and 26 points for three vessel lesion; taking vasospasm G0 as a reference, the influence weight increased by 47.5 points for $\mathrm{G} 2$ and 52.5 points for G3.

According to the formula of prediction model, the risk prediction value of no-reflow after PCI was calculated. The area under Receiver Operating Characteristic (ROC) curve was used to evaluate the alignment and the maximum Youden index was taken as the best critical value of the prediction model. The area under the curve was calculated as 0.860 (Fig. 2), indicating that the alignment had good discrimination. The alignment chart calibration curve was drawn. It was a straight line with slope close to 1 , as shown in fig. 3. HosmerLemeshow goodness of fit test showed $\chi^{2}=10.278$ and $\mathrm{p}=0.246$, indicating that the nomogram model had good

TABLE 1: SINGLE-FACTOR ANALYSIS OF NO-REFLOW AFFECTING

\begin{tabular}{|c|c|c|c|c|c|}
\hline Factor & & $\begin{array}{l}\text { No-reflow group } \\
(n=55)\end{array}$ & $\begin{array}{l}\text { Reflow group } \\
(n=272)\end{array}$ & $\chi^{2} / t$ & $\mathrm{p}$ \\
\hline \multirow{2}{*}{ Gender } & Male & $44(80.00)$ & $209(76.84)$ & \multirow{2}{*}{0.261} & \multirow{2}{*}{0.609} \\
\hline & Female & $11(20.00)$ & $63(23.16)$ & & \\
\hline Age $(y)$ & & $64.87 \pm 11.04$ & $64.15 \pm 10.88$ & 0.447 & 0.656 \\
\hline $\mathrm{BMI}\left(\mathrm{kg} / \mathrm{m}^{2}\right)$ & & $25.58 \pm 2.73$ & $25.16 \pm 2.64$ & 1.070 & 0.285 \\
\hline \multirow{2}{*}{$\begin{array}{l}\text { Complicated } \\
\text { hypertension }\end{array}$} & Yes & $28(50.91)$ & $157(57.52)$ & \multirow{2}{*}{0.864} & \multirow{2}{*}{0.353} \\
\hline & No & 27 (49.09) & $115(42.28)$ & & \\
\hline \multirow{2}{*}{$\begin{array}{l}\text { Complicated } \\
\text { diabetes }\end{array}$} & Yes & $26(47.27)$ & $88(32.35)$ & \multirow{2}{*}{4.485} & \multirow{2}{*}{0.034} \\
\hline & No & $29(52.73)$ & $184(67.65)$ & & \\
\hline \multirow{3}{*}{$\begin{array}{l}\text { Number of coronary } \\
\text { artery lesions }\end{array}$} & Single vessel & $16(29.09)$ & $131(48.16)$ & \multirow{3}{*}{7.159} & \multirow{3}{*}{0.027} \\
\hline & Double vessel & $22(40.00)$ & 87 (31.99) & & \\
\hline & Triple vessel & $17(30.91)$ & $54(19.8)$ & & \\
\hline $\begin{array}{l}\text { Diameter of lesion } \\
\text { vessel }(\mathrm{mm})\end{array}$ & & $3.15 \pm 0.67$ & $3.04 \pm 0.53$ & 1.339 & 0.182 \\
\hline Ischemic time (h) & & $6.23 \pm 1.84$ & $4.79 \pm 1.62$ & 5.872 & 0.000 \\
\hline $\begin{array}{l}\text { Neutrophil } \\
\text { percentage (\%) }\end{array}$ & & $83.56 \pm 4.76$ & $77.48 \pm 7.09$ & 6.085 & 0.000 \\
\hline $\begin{array}{l}\text { White blood cell } \\
\text { count }\left(\times 10^{9}\right)\end{array}$ & & $8.92 \pm 2.57$ & $7.12 \pm 2.15$ & 5.471 & 0.000 \\
\hline $\begin{array}{l}\text { Blood platelet } \\
\text { count }\left(\times 10^{9}\right)\end{array}$ & & $226.83 \pm 65.42$ & $223.87 \pm 61.59$ & 0.332 & 0.748 \\
\hline
\end{tabular}




\begin{tabular}{|c|c|c|c|c|c|}
\hline \multirow{2}{*}{$\begin{array}{l}\text { HDL-C (mmol/l }) \\
\text { LDL-C (mmol/ll) }\end{array}$} & & $1.17 \pm 0.32$ & $1.14 \pm 0.37$ & \multirow{2}{*}{$\begin{array}{l}0.560 \\
1.737\end{array}$} & \multirow{2}{*}{$\begin{array}{l}0.576 \\
0.083\end{array}$} \\
\hline & & $2.64 \pm 0.76$ & $2.41 \pm 0.92$ & & \\
\hline \multirow{7}{*}{ Thrombus grade } & G0 & $3(5.45)$ & $22(8.09)$ & \multirow{9}{*}{17.801} & \multirow{9}{*}{0.002} \\
\hline & G1 & $8(14.55)$ & $46(16.91)$ & & \\
\hline & G2 & $10(18.18)$ & $104(38.24)$ & & \\
\hline & G3 & $28(50.91)$ & 87 (31.99) & & \\
\hline & G4 & 4 (7.27) & $13(4.78)$ & & \\
\hline & G5 & $2(3.64)$ & $0(0.00)$ & & \\
\hline & G0 & $5(9.09)$ & $61(22.43)$ & & \\
\hline \multirow{4}{*}{ Vasospasm grade } & G1 & $29(52.73)$ & $172(63.24)$ & & \\
\hline & G2 & $10(18.18)$ & 38 (13.97) & & \\
\hline & G3 & $11(20.00)$ & $1(0.37)$ & \multirow[t]{2}{*}{37.918} & \multirow[t]{2}{*}{0.000} \\
\hline & $\begin{array}{c}\text { Anterior } \\
\text { descending branch }\end{array}$ & $36(65.45)$ & $165(60.66)$ & & \\
\hline \multirow[b]{2}{*}{ Culprit vessel } & Circumflex branch & $5(9.09)$ & 39 (14.34) & \multirow[b]{2}{*}{1.111} & \multirow[b]{2}{*}{0.606} \\
\hline & $\begin{array}{l}\text { Right coronary } \\
\text { artery }\end{array}$ & $14(25.45)$ & $68(25.00)$ & & \\
\hline \multirow{2}{*}{$\begin{array}{l}\text { Thrombus } \\
\text { aspiration }\end{array}$} & Yes & $21(38.18)$ & $120(44.12)$ & \multirow{2}{*}{0.657} & \multirow{2}{*}{0.418} \\
\hline & No & $34(61.82)$ & $152(55.88)$ & & \\
\hline \multirow{2}{*}{ Eccentric lesion } & Yes & $14(25.45)$ & $41(15.07)$ & \multirow{2}{*}{3.524} & \multirow{2}{*}{0.060} \\
\hline & No & 41 (74.55) & $231(84.93)$ & & \\
\hline \multirow{2}{*}{$\begin{array}{l}\text { Number of } \\
\text { implanted stents } \\
\text { (pieces) }\end{array}$} & 0 & $3(5.45)$ & $21(7.72)$ & \multirow{2}{*}{0.093} & \multirow{2}{*}{0.761} \\
\hline & $\geq 1$ & $52(94.55)$ & $251(92.28)$ & & \\
\hline
\end{tabular}

TABLE 2: MULTI-FACTOR LOGISTIC REGRESSION ANALYSIS OF RISK FACTORS AFFECTING NOREFLOW

\begin{tabular}{|c|c|c|c|c|c|c|c|}
\hline \multirow{2}{*}{ Variable } & \multirow{2}{*}{ Beta (B) } & \multirow{2}{*}{$\begin{array}{l}\text { Standard error } \\
\text { (SE) }\end{array}$} & \multirow{2}{*}{ Wald $\left(\chi^{2}\right)$} & \multirow{2}{*}{$\mathbf{p}$} & \multirow{2}{*}{$\begin{array}{l}\text { Odds ratio } \\
\text { (OR) }\end{array}$} & \multicolumn{2}{|c|}{$95 \%$ Confidence Interval (Cl) } \\
\hline & & & & & & Lower Limb & Upper Limb \\
\hline $\begin{array}{l}\text { Complicated } \\
\text { diabetes (1) }\end{array}$ & 0.656 & 0.383 & 2.930 & 0.087 & 1.928 & 0.909 & 4.087 \\
\hline $\begin{array}{l}\text { Number of coronary } \\
\text { artery lesions }\end{array}$ & & & 6.268 & 0.044 & & & \\
\hline $\begin{array}{l}\text { Number of coronary } \\
\text { artery lesions (1) }\end{array}$ & 0.846 & 0.431 & 3.852 & 0.050 & 2.330 & 1.001 & 5.424 \\
\hline $\begin{array}{l}\text { Number of coronary } \\
\text { artery lesions ( } 2 \text { ) }\end{array}$ & 1.094 & 0.476 & 5.273 & 0.022 & 2.986 & 1.174 & 7.595 \\
\hline Ischemic time & 0.368 & 0.123 & 8.967 & 0.003 & 1.445 & 1.136 & 1.838 \\
\hline $\begin{array}{l}\text { Neutrophil } \\
\text { percentage }\end{array}$ & 0.065 & 0.028 & 5.375 & 0.020 & 1.067 & 1.010 & 1.127 \\
\hline $\begin{array}{l}\text { White blood cell } \\
\text { count }\end{array}$ & 0.284 & 0.094 & 9.105 & 0.003 & 1.329 & 1.105 & 1.598 \\
\hline Thrombus grade & & & 14.101 & 0.015 & & & \\
\hline Thrombus G1 & 0.694 & 1.005 & 0.477 & 0.490 & 2.001 & 0.279 & 14.344 \\
\hline Thrombus G2 & 1.106 & 1.062 & 1.084 & 0.298 & 3.022 & 0.377 & 24.222 \\
\hline Thrombus G3 & 1.184 & 1.009 & 1.378 & 0.240 & 3.267 & 0.453 & 23.585 \\
\hline Thrombus G4 & 3.149 & 1.138 & 7.658 & 0.006 & 23.302 & 2.506 & 216.708 \\
\hline Thrombus G5 & 3.544 & 1.787 & 5.846 & 0.001 & 26.554 & 2.793 & 366.082 \\
\hline Vasospasm grade & & & 25.738 & 0.000 & & & \\
\hline
\end{tabular}


www.ijpsonline.com

\begin{tabular}{lccccccc} 
Vasospasm G1 & -0.008 & 0.522 & 0.000 & 0.988 & 0.992 & 0.357 & 2.761 \\
Vasospasm G2 & 2.138 & 0.598 & 12.787 & 0.000 & 8.479 & 2.627 & 27.363 \\
Vasospasm G3 & 1.974 & 0.865 & 5.210 & 0.022 & 7.198 & 1.322 & 39.201 \\
Normal flow & -13.418 & 2.728 & 24.200 & 0.000 & 0.000 & & \\
\hline
\end{tabular}

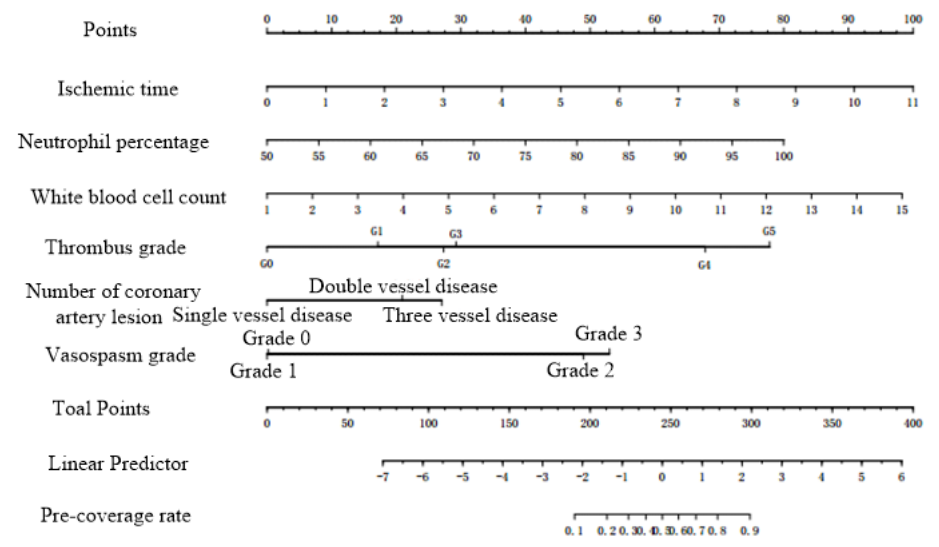

Fig. 1: Nomogram model for predicting the risk of no-reflow after PCI in patients with AMI

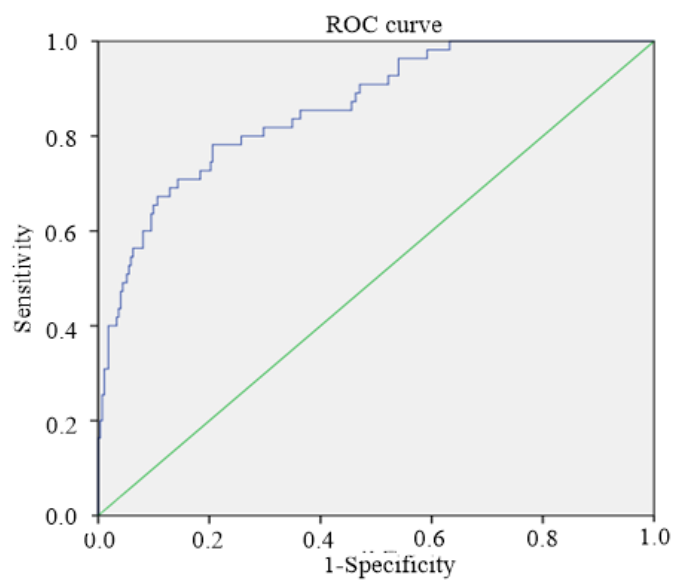

Fig. 2: ROC curve analysis of predicting the risk of no-reflow

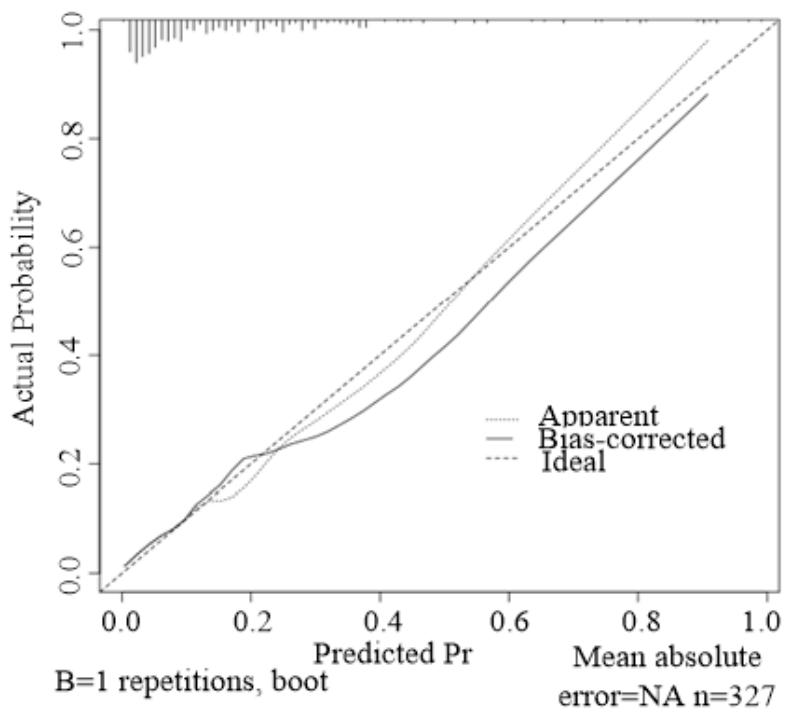

Fig. 3: Calibration curve of prediction model 
consistency in predicting the risk of no-reflow after PCI.

AMI has high mortality and poor prognosis. Clinically, PCI operation is mainly used to open infarcted vessels and restore coronary blood flow for emergency treatment. However, no-reflow is easy to occur during or after PCI. Kumar et al. ${ }^{[7]}$ pointed out that no-reflow can complicate patient's condition and increase the risk of re-hospitalization. Therefore, screening out the risk factors affecting no-reflow after PCI, identifying them as soon as possible and taking intervention measures are of great significance for reducing the incidence of noreflow. A survey on the prediction factors of no-reflow after PCI shows that the incidence of no-reflow after PCI in patients with AMI is related to many factors, such as severe thrombus load, pre-expansion times, local inflammatory reaction and endothelial injury ${ }^{[8]}$.

In this study, 55 cases of 327 patients with AMI had no-reflow after PCI, with the incidence rate of 16.82 $\%$, which was lower than that of Sun et al. ${ }^{[9]}(27.14$ $\%)$ and higher than that of Yuan et al. ${ }^{[10]}(14.46 \%)$. Epidemiological investigation shows that the incidence of no-reflow after PCI is between $10.0 \%$ and $50.0 \%$ and no-reflow can significantly increase the mortality of $\mathrm{AMI}^{[11]}$. In this study, the risk factors affecting noreflow after PCI in patients with AMI were screened. The results showed that the number of coronary artery lesions, ischemic time, neutrophil percentage, white blood cell count, thrombus grade and vasospasm grade were independent risk factors affecting no-reflow. The risk factors screened by logistic regression model were relatively scattered and there might be differences or mutual influences in disease prediction. How to integrate the factors to predict the risk of disease more scientifically and reasonably remains to be solved by clinicians. The nomogram model is one of the models commonly used to predict the risk of illness in recent years. It can integrate various factors and visually show the contribution of various influencing factors to the outcome.

The results of this study showed that ischemic time was a risk factor for no-reflow, which is consistent with clinical research. The nomogram showed that the influence weight of ischemic time increased by 8.5 points for every hour. Clinical studies have shown that ischemia time has an important influence on the progression of coronary microvascular embolism caused by ischemiarelated injury ${ }^{[12]}$. The longer the ischemia time is, the more severe the cerebral hypoxia is and the worse the prognosis is. It has been reported that reperfusion after coronary artery occlusion for $1.5 \mathrm{~h}$ can cause serious capillary injury and capillary lumen obstruction ${ }^{[13]}$. When the ischemia time is over $3 \mathrm{~h}$, coronary artery reperfusion can aggravate ischemia related injury. The nomogram in this study showed that with the increase of neutrophil percentage and white blood cell count, their influence weight also increased. Coronary artery occlusion can lead to neutrophil aggregation and produce a large number of inflammatory mediators. Coronary atherosclerosis is a serious reaction process and the increase of inflammatory factors can aggravate the disease. Neutrophils first appear in the damaged myocardial area and their infiltration can increase blood viscosity and the risk of no reflow ${ }^{[14]}$. Thrombus grade and vasospasm grade are the risk factors affecting no-reflow and their influence weight increases with the increase of thrombus grade and vasospasm grade. Studies have shown that fresh thrombus in blood vessels can increase the risk of no-reflow after PCI ${ }^{[15]}$. Severe contraction of blood vessel wall causes vessel lumen to narrow or close, which affects blood perfusion. In addition, it can also lead to the shedding of atherosclerotic plaque on the blood vessel wall, thus forming thrombus and blocking blood circulation. In addition, thrombus can destroy vascular regulation function and increase vasoconstrictive substances ${ }^{[16,17]}$. The results of this study showed that the number of coronary artery lesions was an independent risk factor affecting no-reflow. The influence weight increased by 20 points for double vessel lesion and 26 points for three vessel lesion. Patients with multi-vessel lesions usually have severe coronary artery lesions such as severe stenosis and long lesions, which increases the risk of microcirculation disturbance at the distal end of blood vessels. Thus, the incidence of no-reflow is increased.

In this study, ROC curve test was used to evaluate the discrimination of nomogram prediction model for predicting no-reflow after PCI in patients with AMI. The area under the curve was calculated as 0.860 , indicating that the nomogram had better discrimination ${ }^{[18]}$. The calibration curve showed that the slope was close to 1 and the Hosmer-Lemeshow goodness of fit test showed that $\chi^{2}=10.278$ and $p=0.246$, suggesting that the nomogram model had good consistency with the actual incidence of no-reflow after PCI with high accuracy.

To sum up, the nomogram prediction model based on the risk factors affecting no-reflow after PCI in patients with AMI, such as number of coronary artery lesion, ischemia time, neutrophil percentage, white blood cell count, thrombus grade and vasospasm grade, had good 
discrimination and consistency. It could provide certain guidance for the prediction and preventive intervention of the risk of no-reflow after PCI.

\section{Conflicts of interest:}

The authors declared no conflict of interest.

\section{REFERENCES}

1. Yu YT, Cai YT. Effect of thrombus aspiration combined with tirofiban on no-reflow phenomenon in patients with STelevation myocardial infarction during PCI. Pract Clin Med 2015;(7):7-11.

2. Al-Jabari AM, Elserafy AS, Abuemara HZ. Effect of chronic pretreatment with beta-blockers on no-reflow phenomenon in diabetic patients with acute ST-elevation myocardial infarction undergoing primary percutaneous coronary intervention. Egypt Heart J 2017;69(3):171-5.

3. Zhang YJ, Liu Y, Zhang XJ. PCI cases of low coronary flow or no coronary reflow in acute myocardial infarction. Chin Gen Pract 2017;20(12):4-8.

4. Pan HF. Progress of no-reflow in patients with acute myocardial infarction undergoing percutaneous coronary intervention. Adv Cardiovasc Dis 2018;39(6):1029-34.

5. Xie T, Zhang X, Cheng B, Huang $M$, Wang $S$, Ou S. Establishment of a prognostic Nomogram model for predicting the first 72-hour mortality in polytrauma patients. Zhonghua wei Zhong Bing ji jiu yi xue 2020;32(10):1208-12.

6. Wang $\mathrm{T}$, Wang $\mathrm{L}$, Yang $\mathrm{H}, \mathrm{Lu} \mathrm{H}$, Zhang $\mathrm{J}$, Li $\mathrm{N}$, et al. Development and validation of nomogram for prediction of malignant transformation in oral leukoplakia: a large-scale cohort study. J Oral Pathol Med 2019;48(6):491-8.

7. Kumar J, O'Connor CT, Kumar R, Arnous SK, Kiernan TJ. Coronary no-reflow in the modern era: a review of advances in diagnostic techniques and contemporary management. Expert Rev Cardiovasc Ther 2019;17(8):605-23.

8. Zhang Y, Wang YZ, Zhang HR, Liu C, Zhang AW, Li CH, et al. Predictive factors and prognostic impact of no-reflow during percutaneous coronary intervention. China Med 2019; 14(9):1302-6.

9. Sun N, Zhang Y, Man LI. Risk factors for no-reflow after emergency coronary intervention in aged patients with acute ST elevation myocardial infarction. Chin J Cardiovasc Rehabil Med 2017;26(1):12-5.
10. Yuan $\mathrm{C}, \mathrm{Ke} \mathrm{YS}, \mathrm{Ke} \mathrm{K}$. Risk factors of no-reflow during primary percutaneous coronary intervention in patients with acute STsegment elevation myocardial infarction. Chin J Evid Based Cardiovasc Med 2016;8(11):1354-6.

11. Li D, Feng X, Li L, Ma XF. Research progress of coronary noreflow. J Xiangnan Univ 2018;20(4):74-8.

12. Salem SA, Haji S, Garg N, Khouzam RN, Jagadish P, Alsafwah $\mathrm{S}$. Occlusion of right coronary artery by microembolization caused by excessive diagnostic catheter manipulation. Ann Transl Med 2018;6(1):20-22.

13. He QJ, Zhang HY, Luo ZX, Yu XL, Wang WH, Luo ZM. Shuxin pill on myocardial microcirculation after acute myocardial infarction and reperfusion in rats. China Pract Med 2011;6(35):31-2.

14. Zhao Q, Zhao G. Progress on predictors, preventive and therapeutic strategies of no-reflow phenomenon in acute myocardial infarction patients undergoing percutaneous coronary intervention. Pract J Card Cereb Pneumal Vasc Dis 2019;27(7):1-4.

15. Ryan TJ, Antman EM, Brooks NH, Califf RM, Hillis LD, Hiratzka LF, et al. 1999 update: ACC/AHA guidelines for the management of patients with acute myocardial infarction: a report of the American college of cardiology/American heart association task force on practice guidelines (committee on management of acute myocardial infarction). J Am Coll Cardiol. 1999;34(3):890-911.

16. Chen ZM, Jiang LX, Chen YP, Xie JX, Pan HC, Peto R, et al. Addition of clopidogrel to aspirin in 45,852 patients with acute myocardial infarction: randomised placebo-controlled trial. Dig World Core Med J 2006;366:1607-1621.

17. Su Q, Liu Y, Lv XW, Dai RX, Yang XH, Kong BH. LncRNA TUG1 mediates ischemic myocardial injury by targeting miR-132-3p/HDAC3 axis. Am J Physiol Heart Circ Physiol 2020;318(2):H332-44.

18. Rossignol P, Iraqi W, Angioi M, Fay R, Nuee J, Ketelslegers $\mathrm{JM}$, et al. H016 Extracellular cardiac matrix biomarkers in patients with acute myocardial infarction complicated by left ventricular dysfunction and heart failure: insights from the ephesus study. Arch Cardiovasc Dis 2009;102:S77.

This is an open access article distributed under the terms of the Creative Commons Attribution-NonCommercial-ShareAlike 3.0 License, which allows others to remix, tweak, and build upon the work non-commercially, as long as the author is credited and the new creations are licensed under the identical terms

This article was originally published in a special issue,
"Diagnostic and Therapeutic Advances in Biomedical Research
and Pharmaceutical Sciences"
Indian J Pharm Sci 2021:83(5)Spl Issue "217-223"

